\title{
Utilizing an Electrical Low Pressure Impactor to Indirectly Probe Water Uptake via Particle Bounce Measurements
}

\author{
Kevin B. Fischer ${ }^{1}$, Giuseppe A. Petrucci ${ }^{1}$ \\ ${ }^{1}$ Department of Chemistry, The University of Vermont, Burlington, VT, 05405, USA \\ Correspondence to: Giuseppe A. Petrucci (giuseppe.petrucci@uvm.edu)
}

\section{Supplemental Information}

\section{Comparison to Bounce Factor Method}

The modified, abridged approach to particle bounce presented herein was also compared with the complete method described previously,(Jain and Petrucci, 2015) where bounce factor (BF) was determined (Fig. S1). This comparison was completed to ensure that the modified, abridged approach is not the reason for the persistence of particle bounce under high chamber RH for the systems studied here. Good agreement was observed between the methods, especially when one considers that the complete method requires two separate experiments where the same nominal conditions are established for two consecutive experiments, one of which uses sintered impaction plates to shut down bounce and the other smooth plates to favor bounce. In this comparison, $\alpha$-pinene derived SOA was generated with a maximum $\mathrm{C}_{\mathrm{SOA}}$ of $48-52 \mu \mathrm{g} \mathrm{m}^{-3}$ observed.

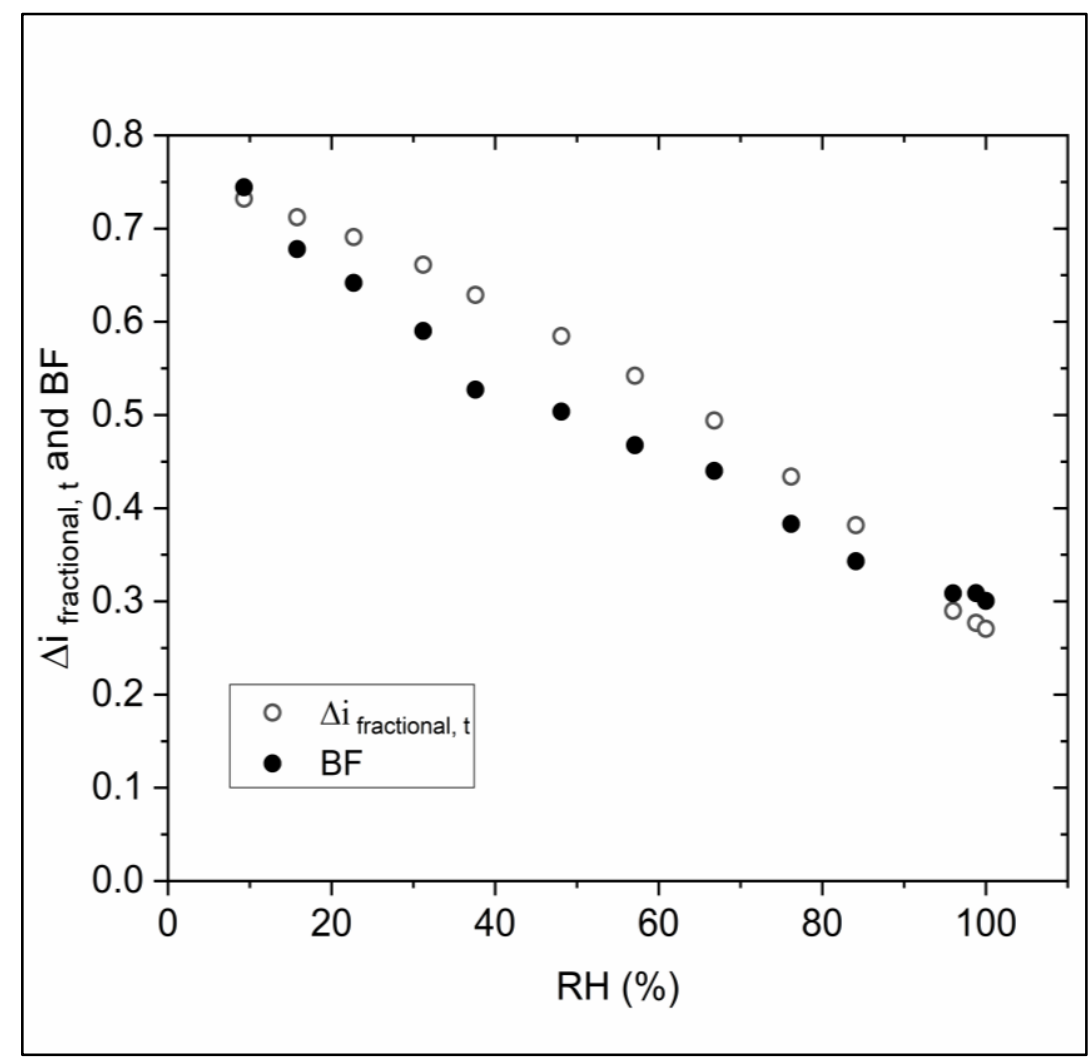

Figure S1. Comparison of particle phase state as measured by the bounce factor method (Jain and Petrucci, 2015) and modified method used in this work. $\alpha$-pinene derived SOA was generated via ozonolysis in a $750 \mathrm{~L}$ Teflon environmental chamber. Maximum $\mathrm{C}_{\mathrm{SOA}}$ observed was $48-52 \mu \mathrm{g} \mathrm{m}^{-3}$. 


\section{References}

Jain, S., and Petrucci, G. A.: A New Method to Measure Aerosol Particle Bounce Using a Cascade Electrical Low Pressure Impactor, Aerosol Sci. Technol., 49, 390-399, 10.1080/02786826.2015.1036393, 2015. 